\title{
Promovendo o desenvolvimento linguístico e o raciocínio lógico em práticas de letramento com uso de recursos tecnológicos
}

\author{
Paulo Ricardo dos Santos - Universidade Feevale - paulo.s@feevale.br \\ Débora Nice Ferrari Barbosa - Universidade Feevale - deboranice@feevale.br \\ Carla Rosana da Silva - Associação de Assistência em Oncopediatria \\ carlasilvaamo@gmail.com \\ Jorge Luís Victória Barbosa - Universidade do Vale do Rio do Sinos - \\ jbarbosa@unisinos.br
}

Resumo: Este artigo apresenta práticas pedagógicas com uso de dispositivos móveis tablets no ensino-aprendizagem de crianças e adolescentes atendidos por uma instituição de apoio ao tratamento oncológico. As práticas focaram no letramento dos sujeitos sob a perspectiva da leitura, escrita e raciocínio lógico, desenvolvidas com uso de aplicativos e jogos diversos. A metodologia de pesquisa utilizada foi a pesquisaação. Em 2017, as oficinas trabalharam gêneros textuais em práticas sobre sustentabilidade e em 2018 trabalhou-se com um roteiro de leitura sobre o livro "O menino que aprendeu a ver", de Ruth Rocha. Os resultados demonstram que práticas com tecnologia favorecem os processos de letramento e raciocínio lógico, além de motivarem e contribuírem para a aprendizagem dos sujeitos.

Palavras Chave: Recursos tecnológicos, escrita, leitura, letramento, mobilidade.

\section{Promoting the linguistic development and the logical reasoning in literacy practices using technological resources}

\begin{abstract}
This paper presents the pedagogical practices done with the use of mobile tablet devices in the teaching and learning of children and adolescents assisted by an oncologic care institution. The practices focused on the literacy of subjects from the perspective of reading, writing and logical reasoning, developed using several applications and games. The research methodology used was action research. In 2017, the workshops worked with textual genres and the theme of sustainability, while in 2018 they worked on a reading script on Ruth Rocha's book "The Boy Who Learned to See". The results show that practices with technology favors the processes of literacy and logical reasoning, besides motivating and contributing to the learning of the subjects.
\end{abstract}

Keywords: Technological resources, writing, reading, literacy, mobility.

\section{Introdução}

Jovens em idade escolar utilizam diariamente dispositivos móveis, tais como smartphones e tablets, como parte de uma cultura digital que usa a tecnologia para comunicação, entretenimento e aprendizagem. Surge, assim, uma nova forma de aprender, a aprendizagem com mobilidade (Saccol et al. 2010), caracterizada pelo uso em qualquer lugar de recursos tecnológicos para acesso, produção e compartilhamento de conhecimento. Dentre esses recursos, destacam-se também jogos digitais, que podem ser usados no processo de ensino e aprendizagem de uma forma lúdica e desafiadora (Araújo \& Carvalho, 2018). Nesse sentido, a mobilidade, os jogos e a internet trazem elementos que potencializam um processo de aprendizagem mais significativo.

$\mathrm{O}$ uso de tecnologias digitais nos processos educativos tem se tornado uma área de 
grande pesquisa e debate (Matos et al., 2019), uma vez que práticas pedagógicas realizadas com uso de aplicativos, jogos, softwares, sites, entre outros, podem promover uma nova percepção dos estudantes quanto ao acesso, produção e compartilhamento de conhecimento. Com os jogos digitais, é possível desenvolver uma aprendizagem significativa a nível de raciocínio lógico, leitura e escrita, uma vez que um jogo requer o uso de estratégias e habilidades diversas para resolução de problemas (Ruis et al, 2019). Nas práticas de leitura e escrita, há diversos aplicativos que possibilitam a produção de diferentes gêneros textuais. Cabe ao professor orientar seus estudantes quando a esses recursos e ensiná-los a lidar com os textos e informações disponíveis na web (Ramos \& Villaça, 2019). Nesse cenário, percebe-se que ser alfabetizado, isto é, saber ler e escrever, não é o bastante. É necessário entender o que se lê, relacionar os textos, compreender o propósito comunicativo de cada gênero textual, saber indagar e responder à informação, saber usar a linguagem para comunicar-se. Entra em debate, então, a perspectiva do letramento, que é o uso contextualizado de leitura e escrita visando a interação social (Soares, 1998) (Travaglia, 2015).

$\mathrm{O}$ uso de tecnologias móveis nos processos educativos possibilita que a aprendizagem ocorra em espaços não formais de educação, dando suporte para o crescimento da educação não-formal ou não escolar (Zuchetti e Moura, 2010), na qual a aprendizagem ocorre com características distintas dos espaços formais. Nesse sentido, ao desenvolvermos oficinas de aprendizagem com mobilidade em uma instituição de apoio ao tratamento oncológico, trabalhamos o desenvolvimento de leitura, escrita e raciocínio lógico em um ambiente não-formal, permitindo que as práticas sejam melhor adaptadas às necessidades do público-alvo, que são pacientes em tratamento oncológico e seus familiares, de idades entre 4 e 18 anos.

Sendo assim, surgem diferentes questões: (i) Como os recursos tecnológicos podem contribuir para o letramento dos sujeitos considerando desenvolvimento de escrita, leitura e raciocínio lógico?; (ii) como o uso de recursos tecnológicos, em especial, aplicativos e jogos digitais, podem motivar e contribuir para a aprendizagem?

Para responder a essas indagações, este artigo apresenta dados referentes ao período das oficinas entre 2017/2018 e está organizado da seguinte forma: além desta introdução, na seção 2, descreve-se a metodologia utilizada. Na seção 3, apresentam-se as práticas realizadas, respectivamente, em 2017 e 2018, bem como os resultados. Na sequência, na seção 4, são discutidos os resultados respondendo as indagações desta introdução, para, então, encerrar com as considerações finais.

\section{Metodologia}

As práticas do projeto "Oficina de aprendizagem com mobilidade" são desenvolvidas semanalmente em uma instituição de apoio ao tratamento oncológico, caracterizando um espaço de educação não-formal ou não escolar no qual o aprender ocorre de forma distinta de espaços formais como escolas públicas ou privadas (Zuchetti \& Moura, 2010). Nas oficinas, são realizadas práticas pedagógicas com uso de dispositivos móveis tablets no ensino-aprendizagem de pacientes em tratamento oncológico e seus familiares, que também são atendidos pela instituição. Os sujeitos, crianças e adolescentes, apresentam dificuldades referentes ao afastamento escolar, causado pelos períodos de baixa imunidade e tratamento. Logo, a escolha por utilizar tecnologias digitais para desenvolver leitura, escrita e raciocínio lógico (Silva \& Tarouco, 2018) justifica-se pelo fato dessas serem habilidades necessárias para todos os indivíduos.

A metodologia adotada foi a pesquisa-ação (Thiollent, 2003; Tripp, 2005), do tipo qualitativa, na qual os pesquisadores atuam em contato direto com o objeto de pesquisa, resolvendo problemas e conduzindo intervenções sistemáticas, nas quais 0 
monitoramento e avaliação dos resultados pode indicar ou não a necessidade de um novo planejamento e novas ações, sempre em busca de um objetivo que pode ser reformulado ou ampliado conforme os rumos da pesquisa (Picheth et al., 2016).

Dentre as diversas formas de estabelecer as etapas que caracterizam o processo de pesquisa-ação, optamos por adaptar aquelas referenciadas por Tripp (2005) considerando as seguintes etapas: (a) Objetivos: Aqui, definimos o objetivo geral (desenvolvimento de leitura, escrita e raciocínio lógico, que permanece o mesmo para cada ano) e objetivos específicos (com relação à temática ou recursos tecnológicos, que varia conforme o ano/semestre); (b) Planejamento Inicial: Aqui, traçamos $\mathrm{o}$ planejamento micro das oficinas: O que será realizado em cada oficina? Quais aplicativos/jogos/sites serão utilizados? Que tipo de atividades serão produzidas?

Tendo iniciado as oficinas, temos: a) Ação: Aplicação das oficinas e das atividades planejadas. b) Monitoramento: Observação constante, coleta de resultados, escrita de diário de pesquisa, monitoramento da resposta dos sujeitos. c) Avaliação: Qual é a resposta dos sujeitos em relação às práticas? Como está sendo o desenvolvimento dos objetivos? Que ações podem ser tomadas para ampliar ou corrigir os resultados? d) Novo Planejamento: Aqui, fazemos um novo planejamento dos encontros a nível micro, estabelecendo novas atividades e, dependendo os resultados, manter as ações; e) Nova ação: Aqui, fazemos a intervenção nas oficinas conforme o novo planejamento; f) Novo monitoramento: Aqui, continuamos coletando dados e observando como os sujeitos reagem às intervenções; g) Nova avaliação: Analisamos os resultados provenientes da intervenção e comparamos com os dados obtidos anteriormente, de modo a compreender se estamos no caminho certo ou se é necessária uma nova intervenção. Assim, o ciclo segue até que tenhamos atingido os objetivos.

Como coleta de dados, as produções dos alunos são salvas na pasta do projeto no Google Drive e são feitos relatórios de cada encontro, destacando a descrição da oficina, a observação dos pesquisadores, facilidades ou dificuldades apresentadas pelos sujeitos, entre outras informações.

Na seção 3, a seguir, descrevem-se as práticas realizadas em 2017 e 2018, analisadas em dois aspectos: a) como os recursos tecnológicos foram utilizados; b) como foi o desenvolvimento de escrita, leitura e raciocínio lógico.

\section{3 - Práticas com tecnologias}

\subsection{As oficinas em 2017: trabalhando com gêneros textuais e sustentabilidade}

Em 2017 desenvolvemos a temática de Sustentabilidade dos Recursos Hídricos, tema que também estava sendo trabalhado no Laboratório de Objetos de Aprendizagem da Universidade Feevale, no qual foi desenvolvido um jogo sobre o assunto chamado "Geração Água". Nas reuniões iniciais do ano, a equipe discutiu as propostas e objetivos para as oficinas. Também definiu-se nesse momento a temática (utilização sustentável dos recursos hídricos), que tipos de atividades desenvolveríamos (produções textuais, uso de jogos digitais, fotografia, desenhos, entre outros) e selecionamos alguns recursos tecnológicos, como Google Docs, Comic Stript e Autodesk Sketchbook.

As oficinas iniciaram no mês de março e seguiram até dezembro, totalizando 31 encontros, dos quais participaram, ao todo, 11 crianças e adolescentes, de idades entre 6 e 18 anos. Desses, atendemos 4 pacientes em tratamento oncológico, dos quais dois estavam com os estudos trancados (e atrasados) devido aos períodos de baixa imunidade. Além disso, o número de participantes variou mês a mês e apenas duas alunas participaram de todas as oficinas do ano, sendo uma delas paciente. Nas subseções a seguir, descrevem-se os resultados obtidos. 


\subsubsection{Recursos tecnológicos utilizados}

Durante o ano, foram utilizados diversos recursos tecnológicos, os quais, de acordo com suas funcionalidades, foram adaptados às práticas pedagógicas. Destacam-se o aplicativo Google Docs, usado para produções textuais; Comic Stript It, aplicativo para criação de histórias em quadrinhos; Geração Água, jogo sobre uso sustentável dos recursos hídricos; Video Show, aplicativo para criação e edição de vídeos; Kahoot, site/aplicativo para questionários em formato de jogo, Autodesk Sketchbook, aplicativo para produção de desenhos, entre outros. O Google Docs foi utilizado em diversas práticas de escrita ao longo do ano, por ser de fácil utilização e pelos textos ficarem salvos automaticamente online. Foram também utilizados jogos e aplicativos sobre a temática, dentre os quais destaca-se o jogo Geração Água e os aplicativos Nossa Água e Xuxa - Água para que te Quero, os quais, além de trazerem várias informações aos alunos, também possuíam jogos nos quais os sujeitos puderam aprender jogando. Cabe destacar o uso dos aplicativos Comic Stript IT, que foi utilizado em duas atividades diferentes, e Kahoot, utilizado para revisão da temática. Esses aplicativos foram escolhidos em função do perfil da atividade e do objetivo.

\subsubsection{Desenvolvimento de leitura, escrita e raciocínio lógico}

Dentre as atividades que consideramos mais engajadoras e que mais contribuíram para o desenvolvimento de escrita, leitura e raciocínio lógico, consideramos:

a) Produção de receita para salvar a natureza: Essa atividade envolveu a aprendizagem sobre gênero textual receita. Inicialmente, discutimos com os alunos as características de uma receita, analisando textos encontrados na internet. Em seguida, os alunos foram desafiados a produzir uma receita para salvar a natureza, que devia conter: ingredientes, modo de preparo e rendimento. Para escrita, os alunos usaram o aplicativo Google Docs. Na sequência, os alunos transformaram sua receita em um vídeo por meio do aplicativo Vídeo Show, utilizando imagens, legendas, som e efeitos de transição.

b) Jogo Geração Água: Para aprenderem sobre a temática, os alunos jogaram o jogo Geração Água. No jogo, o usuário deve auxiliar uma família a desenvolver e manter hábitos sustentáveis de uso da água, alterando a estrutura da casa e eliminando o desperdício. Esse jogo forneceu, por meio da diversão de "vencer", uma base de conhecimento muito grande. Por exemplo, os alunos se deram conta de que toda vez que não conseguiam mudar um hábito das personagens, como deixar a torneira de água correndo, perdia-se dinheiro, impedindo que fizessem melhorias na casa. Assim, o jogo foi um excelente recurso para desenvolver o raciocínio lógico e a temática.

\subsection{As oficinas em 2018: Roteiro de leitura adaptado ao uso de tecnologias}

Em 2018, participaram das oficinas, ao todo, 5 sujeitos, de idades entre 4 e 13 anos. Nesse ano, trabalhamos com a temática "identidade e história pessoal", de modo que os alunos pudessem ter um ambiente livre para expressar suas opiniões, contar suas histórias e compartilhar suas experiências com os colegas. Dessa vez, os 5 sujeitos participaram de praticamente todas as oficinas, sendo 1 deles paciente, em estágio controlado da doença, e, os demais, familiares. As oficinas iniciaram em março e seguiram até o mês de julho, contabilizando, ao todo, 17 encontros.

No planejamento de início do ano, decidimos trabalhar no ambiente do Google Classroom e explorar a potencialidade do uso de uma sala de aula virtual. Para utilizálo, criamos uma turma no aplicativo usando a conta Google do projeto e, para cada aluno, utilizamos contas Google criadas para as oficinas. Em cada oficina, postávamos as atividades no ambiente e os alunos interagiam e faziam atividades pelo aplicativo. 
Durante o semestre, surgiu a possibilidade de desenvolver uma prática em conjunto com o Mestrado Profissional em Letras da Universidade Feevale. Alunos do curso haviam desenvolvido roteiros de leitura com uso de tecnologias e, sendo uma das professoras do Mestrado parceira do projeto, um dos roteiros foi escolhido para ser aplicado nas oficinas. Dessa forma, seguindo a pesquisa-ação, o projeto do Roteiro de Leitura sobre o livro "O menino que aprendeu a ver", de Ruth Rocha, deu origem a uma intervenção no planejamento anterior, na qual passamos a desenvolver novas atividades no ambiente virtual do Google Classroom e leitura e análise do livro em três formas: leitura do livro físico, leitura de versão em $P D F$ e vídeo do livro no aplicativo Youtube. Além disso, foram produzidos textos escritos manualmente e também de forma digital no aplicativo Google Docs, inspirados no livro.

\subsubsection{Recursos utilizados e práticas pedagógicas}

Alguns dos recursos utilizados no ano anterior foram novamente aproveitados nas oficinas, tais Google Docs e Comic Stript It. Além disso, foram utilizados novos recursos, como Mentimeter, que é um site/aplicativo para questionários e apresentações interativas e o Google Classroom, a sala de aula virtual do Google, o qual foi um dos principais recursos utilizados. Nele, disponibilizamos textos para os alunos, aplicamos questionários para responderem, compartilhamos recados com a turma, abrimos murais e fóruns para discussão e também incentivamos os alunos a postarem suas produções, bem como lerem as dos colegas e fazerem comentários/sugestões.

Com relação às outras ferramentas, o Google Docs foi utilizado na produção de dois textos dentro do projeto do Roteiro de Leitura. Já o Mentimeter foi utilizado para que os sujeitos respondessem questões sobre gostos e interesses pessoais e foi um dos recursos que os alunos mais gostaram.

Dentre os jogos indicados pelos pesquisadores, o principal foi o Alpha Beat Cancer, que possui a temática acerca dos cuidados com o câncer infantil, o qual os alunos gostaram de jogar e puderam aprender sobre cuidados que o paciente deve ter.

\subsubsection{Desenvolvimento de escrita, leitura e raciocínio lógico}

Dentre as atividades que consideramos mais engajadoras e que mais contribuíram para o desenvolvimento de escrita, leitura e raciocínio lógico temos:

a) Produção de narrativa visual: Esta foi baseada na crônica "Circuito Fechado", de Ricardo Barros, que conta um dia na história de um homem utilizando apenas nomes de objetos. Inicialmente, fizemos a leitura do texto e discutimos sobre seu conteúdo. $\mathrm{Na}$ sequência, os alunos tiveram de produzir uma história em quadrinhos contando como é um dia em suas vidas, mas apenas poderiam utilizar imagens e palavras chave. Para tal, utilizaram o aplicativo Comic Stript IT e tiveram de organizar as imagens sequencialmente de modo que cada uma representasse algum elemento de sua rotina, desenvolvendo seu letramento através do raciocínio lógico, escrita e leitura.

b) Roteiro de Leitura: O livro "O menino que aprendeu a ver", de Ruth Rocha, conta história de um garoto que não entende os símbolos que enxerga nos objetos do seu dia a dia. Quando começa a estudar, o garoto percebe que os símbolos são letras e agora ele consegue ver o que eles significam. A partir desse livro, os alunos fizeram sua leitura, responderam questionários de interpretação textual no Google Classroom e produziram textos inspirados pela história, utilizando o aplicativo Google Docs.

\section{Análise e discussão dos resultados}

Nesta seção, retomamos as indagações levantadas na introdução deste trabalho, analisando com exemplos das produções feitas nas oficinas. 


\subsection{Práticas de letramento - desenvolvendo leitura, escrita e raciocínio lógico}

Retomando os questionamentos de pesquisa, com relação à primeira, "Como os recursos tecnológicos podem contribuir para o letramento dos sujeitos considerando desenvolvimento de escrita, leitura e raciocínio lógico, percebe-se que as práticas com tecnologias permitiram que os estudantes aprimorassem seus aspectos de leitura e escrita por meio do trabalho com gêneros textuais e dos desafios de produzir textos variados em aplicativos com recursos diversos de escrita, inserção de imagens e ícones, layouts, cores, entre outros, aprimorando, consequentemente, seu raciocínio lógico também, o que contribuiu significativamente para seu letramento.

Para demonstrar como foi esse desenvolvimento de leitura e escrita, usaremos como exemplo amostras de textos produzidos pela aluna $\mathrm{J}$, de 10 anos, paciente da instituição. Os textos demonstram como as práticas com tecnologia favoreceram o letramento da participante e demonstram a evolução de seu desenvolvimento linguístico.

O texto 1 foi feito no aplicativo Google Docs e tinha como objetivo desenvolver uma narrativa inspirada em uma imagem que mostrava o antes e depois de um rio poluído. A figura 01 mostra o texto e percebe-se que a estudante escrevia textos com poucos detalhes e informações, tendo dificuldades ortográficas distintas. Essas dificuldades foram trabalhadas ao longo das oficinas seguintes.

A um tempo atrás, um homem queria construir uma fábrica esse homem foi na floresta e desmatou $:$ toda ela. Essa floresta era cheia de árvores, flores peixes pulando no lago e um céu lindo.

Esse homem destruiu toda a floresta, depois construiu mais outras e poluindo toda a floresta. bonita. (-)

Depois as fábricas faliram e a floresta voltou a ser como era antes calmo e

Figura 01 - Texto 01: Narrativa sobre Meio Ambiente

Ao longo das semanas, o trabalho com a linguagem foi desafiando os sujeitos a produzirem outros tipos de texto, com lógicas diferentes de escrita e estrutura. A Figura 02 mostra o texto "anúncio publicitário comercial", na qual os alunos pensaram em estratégias de persuasão para convencer o leitor a comprar um produto inventado por eles. Dessa forma, utilizando o aplicativo Autodesk Sketchbook, J. teve de pensar no preço, escolher uma imagem do objeto, um slogan, frases persuasivas, cores e layouts. Percebe-se que J conseguiu articular diversos conhecimentos linguísticos no anúncio, conforme visto na Figura 02.

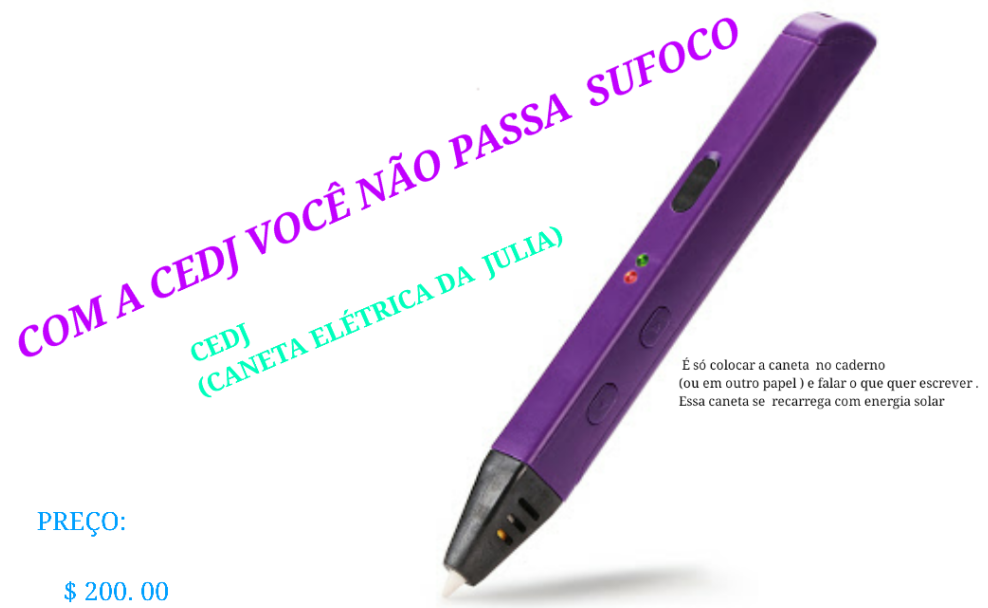

Figura 02 - Texto 02: Anúncio publicitário comercial 
Esse texto serviu como uma preparação para que os alunos estivessem aptos a desenvolverem um outro tipo de texto persuasivo, dessa vez em relação à temática de sustentabilidade. Novamente, a aluna fez um uso coerente da linguagem persuasiva, usando seus conhecimentos linguísticos para convencer o leitor a preservar a água. A figura 03 demonstra o texto produzido no aplicativo Autodesk Sketchbook:

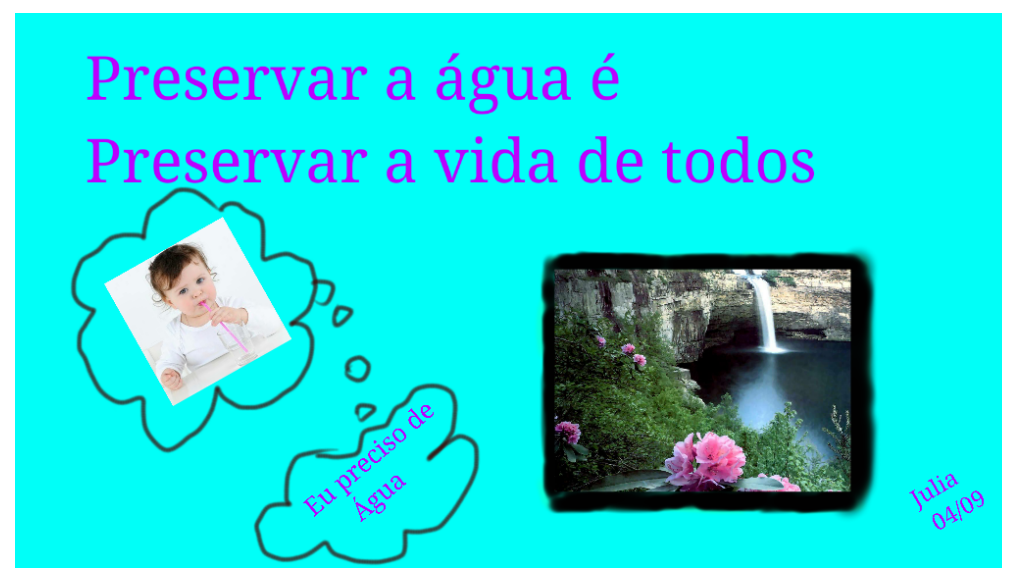

Figura 03 - Texto 03: Anúncio publicitário ambiental

Em 2018, J. continuou participando das oficinas. Durante o Roteiro de Leitura, foram oportunizadas diversas atividades de leitura e interpretação textual no Google Classroom de modo a preparar os sujeitos para a produção de 2 textos narrativos, nos quais os alunos iriam primeiro escrever no papel e, em seguida, reescreverem a história no aplicativo Google Docs. Assim, poderíamos auxiliar na ortografia e observar quais seriam as diferenças entre as duas versões do texto. $\mathrm{J}$ chegou a produzir a narrativa em folha pautada, porém, teve de se ausentar das últimas oficinas para consultas médicas. Para fins desta análise, trazemos a imagem desse texto, conforme figura 04 , no qual se percebe como as práticas voltadas para o letramento possibilitaram que $\mathrm{J}$ progredisse na construção do texto e organização das informações, em comparação ao texto 01 .

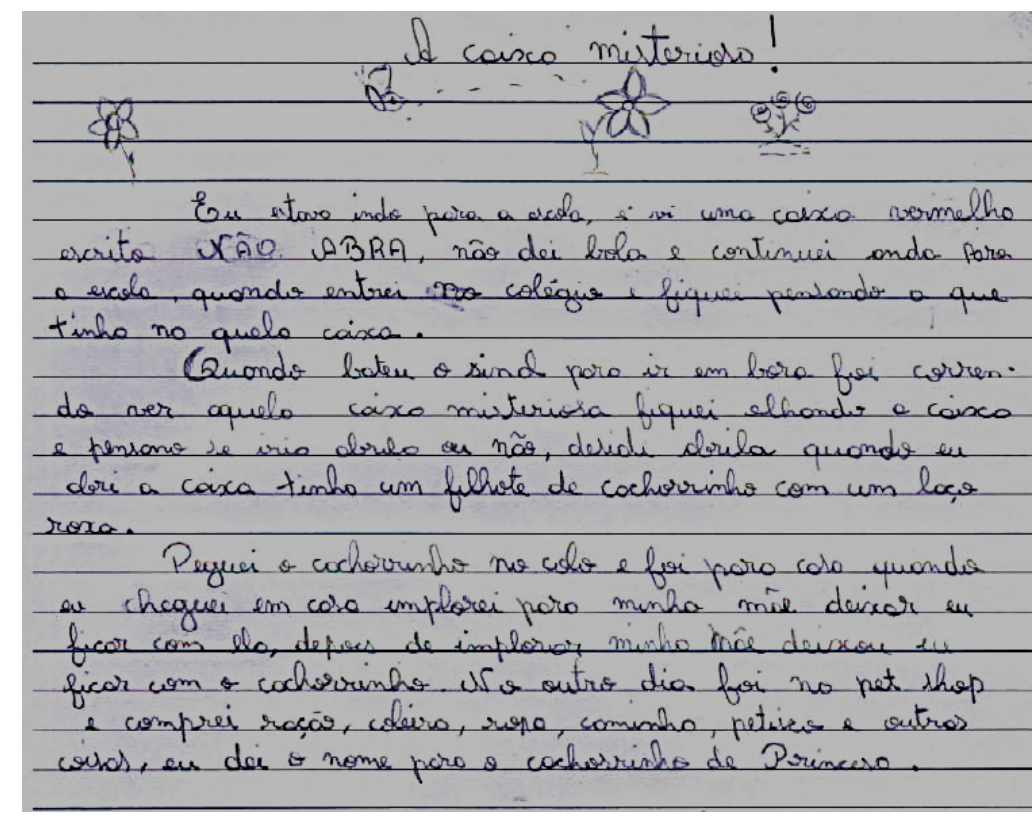

Figura 04 - Texto 04: Narrativa escrita em folha pautada no Roteiro de Leitura 


\subsection{Dos recursos tecnológicos e reflexos na aprendizagem}

Com relação à questão "como o uso de recursos tecnológicos, em especial, aplicativos e jogos digitais, podem motivar e contribuir para a aprendizagem?", percebe-se que o uso dos dispositivos móveis tablets forneceu diferentes recursos para o desenvolvimento de leitura, escrita e raciocínio lógico. Cada aluno utilizando um tablet pôde escrever, desenhar, fotografar, assistir vídeos, acessar sites, jogar jogos, entre outros. Assim, as possibilidades de desenvolvimento tornaram-se amplas e demandavam uma seleção adequada de aplicativos e a criação de práticas em que fosse possível explorar o potencial desses recursos, selecionados por meio de pesquisas na Google Playstore, de acordo com os tipos de produções que gostaríamos de realizar.

Quanto ao uso de jogos, trazemos aqui o exemplo do jogo Geração Água, usado na temática de sustentabilidade dos recursos hídricos. Esse jogo promoveu excelentes aprendizagens em relação à leitura, escrita e raciocínio lógico aos alunos, que puderam fazer conexões entre a temática e sua vida pessoal. A seguir, disponibilizamos as respostas de um questionário respondido no aplicativo Google Docs pelo paciente M., de 16 anos, após jogar o jogo.

a) Qual é a sua opinião sobre o jogo Geração Água? Eu achei que ele é muito legal e divertido pois influencia pessoas a não desperdiçar água.

b) Você compreendeu a proposta do jogo? O jogo explica como ele funciona pelas dicas que ele dá mas está na cara que é um jogo sobre o desperdício de água, o jogo quer que você faça com que a família do jogo não desperdice água.

c) Foi possível fazer uma relação entre a temática das situações vivenciadas no jogo e o seu dia a dia? Na minha casa estão umas coisas que tem na minha casa como a caixa de água e o filtro de ralo.

d) Você acha que os jogos trazem benefícios para a aprendizagem? Sim porque alguns jogos têm coisas que nós lidamos na nossa vida como não desperdiçar água comer alimentos saudáveis mas também existem jogos que podem influenciar errado como roubar ou matar alguém.

Pelas respostas de M, percebe-se que o uso do jogo motivou e contribuiu para sua aprendizagem pelas relações que estabeleceu entre o assunto abordado e suas vivências. Isso demonstra que foi adequada a escolha do jogo Geração Água para o assunto de sustentabilidade dos recursos hídricos.

Para desenvolver aprendizagens significativas em que os sujeitos pudessem aprender diante de situações problema, foram elaboradas práticas explorando a mobilidade dos tablets, dentre as quais destacamos duas, feitas em 2017. A primeira, conforme figura 05, foi uma atividade em que os alunos deveriam investigar locais da instituição em que pudesse ocorrer o desperdício de água e depois produzirem um texto com informações sobre como cuidar da água nesses locais. De posse dos tablets, os alunos se movimentaram pelos espaços da instituição, registraram fotos, pensaram nos problemas que poderiam surgir e criaram textos no aplicativo Comic Stript It.

A segunda prática que envolveu o uso da mobilidade foi "Reportagem sobre sustentabilidade", na qual os sujeitos assumiram o papel de repórteres e entrevistaram funcionários da instituição, investigando como as pessoas cuidam da água. Assim, novamente, os sujeitos puderam utilizar a mobilidade dos tablets, filmando suas entrevistas, compartilhando os vídeos com os colegas e discutindo suas descobertas. 


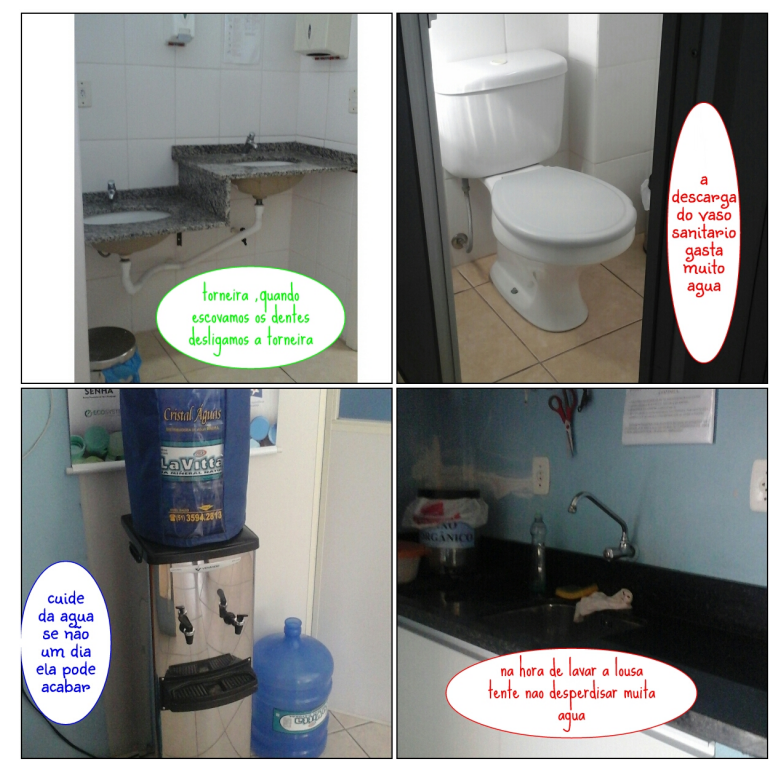

Figura 05 - Atividade envolvendo mobilidade dos tablets

Em 2018, participaram crianças de idades bem distintas, entre 4 e 13 anos. Diante dessa questão, era necessária uma seleção adequada dos recursos para que cada sujeito pudesse produzir conforme suas habilidades. Assim, foi proposto na atividade "Narrativa Visual" que os alunos produzissem uma narrativa sobre um dia em suas vidas, utilizando imagens e palavras chave, inspirados na crônica "Circuito Fechado", de Ricardo Ramos. A figura 06 mostra a narrativa visual da aluna R, de 4 anos, feita no aplicativo Comic Stript It, cuja facilidade de inserção de imagens e edição possibilitou que $\mathrm{R}$ produzisse a atividade. Embora ainda esteja aprendendo as formas básicas das letras e junção de sílabas, $R$ demonstrou compreensão da proposta, pois, com ajuda dos pesquisadores, escolheu as imagens que melhor descreviam sua rotina.

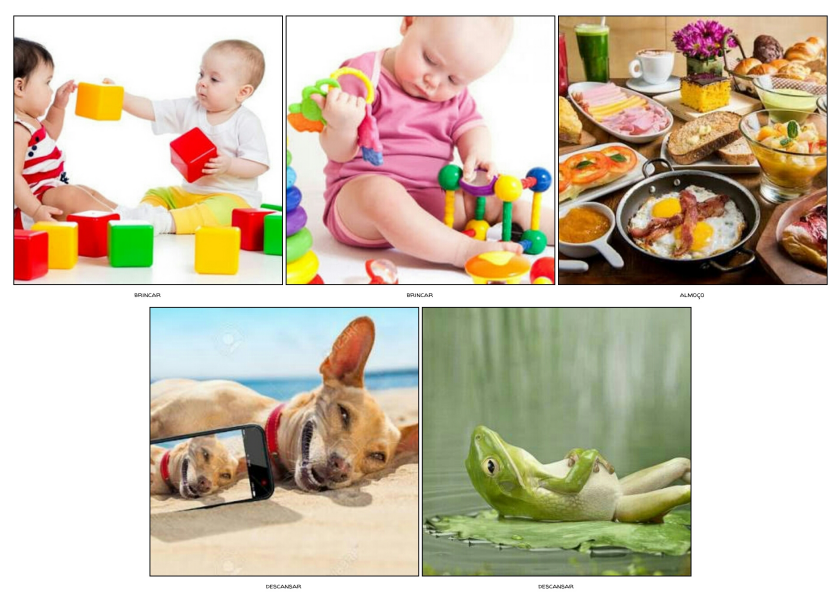

Figura 06 - Exemplo de texto produzido no aplicativo Comic Stript It

\section{Considerações Finais}

Conforme os resultados apresentados, práticas pedagógicas com uso de tecnologias podem motivar a aprendizagem e conduzir os alunos a novos desafios com relação ao acesso e produção de conhecimento. Para tal, é necessário uma seleção adequada dos recursos tecnológicos e elaboração de práticas pedagógicas em que seja possível para os sujeitos desenvolverem seus conhecimentos e explorarem de forma significativa os recursos tecnológicos. 
Em relação à continuidade do projeto, as oficinas de aprendizagem com mobilidade continuam sendo desenvolvidas em 2019, nas quais está sendo trabalhado uma prática integrada que envolve o uso de jogos de Role Playing Game (Jogos de interpretação de papéis) com um jogo sobre Saneamento Ambiental. Pretende-se, ainda, estudar formas de disponibilizar essas práticas publicamente, seja por meio de repositórios de aprendizagem ou em sites apropriados, de modo que sirvam de inspiração para o desenvolvimento de projetos educacionais com uso de recursos tecnológicos em contextos de educação não escolar. Dessa forma, espera-se, com as oficinas do projeto, além de auxiliar na aprendizagem dos sujeitos atendidos, também contribuir para o estudo e debate acerca das práticas com tecnologias digitais.

\section{Agradecimentos}

Os autores agradecem ao Conselho Nacional de Desenvolvimento Científico e Tecnológico - CNPq, à Universidade Feevale pelo apoio à pesquisa e também à Associação de Assistência em Oncopediatria - AMO CRIANÇA, pela disponibilidade para a realização do projeto.

\section{Referências}

ARAÚJO, I.; CARVALHO, A. A. Gamificação no ensino: casos bem-sucedidos. Revista Observatório, v. 4, n. 4, p. 246-283, 29 jun. 2018.

MATOS, J. D. V.; SILVA, J. R. C.; RIBEIRO, A. F. S.; GOMES, R. M. M., FERREIRA, J. C.; MATOS, F. B. Aprendizagem Significativa por meio do Uso de TICs: Levantamento das Produções da Área de Ensino de 2016 a 2018. Revista Renote. v. 17, n. 1, 2019.

PICHETH, S. F.; CASSANDRE, M. P.; THIOLLENT, M. J. M. Analisando a pesquisaação à luz dos princípios intervencionistas: um olhar comparativo. Educação (Porto Alegre), 39(esp.), s3-s13. 2016.

RAMOS, M. A. S.; VILAÇA, I. M. B. O contributo da narrativa digital para o desenvolvimento da fala num caso de rubinstein-taybi: estudo de caso. Revista Observatório, v. 5, n. 1, p. 299-335, 14 jan. 2019.

RUIS, L. S.; TAMARIZ, A. D. R.; BATISTA, S. C. F. Mobile games de entretenimento em práticas pedagógicas interdisciplinares. Revista Renote. v. 17, n. 1, 2019.

SACCOL, A. I. C. Z.; SCHLEMMER, E.; BARBOSA, J. L.V. M-learning e Ulearning: Novas Perspectivas da Aprendizagem Móvel e Ubíqua; 1. ed. São Paulo: Pearson Prentice Hall, 162p, 2010.

SILVA, P. F.; TAROUCO, L. M. R.; A Construção do Pensamento Formal pelo Adolescente em Ambiente Virtual. Revista Renote. v. 16, n. 1, 2018.

SOARES, M. Letramento: tema em três gêneros. Belo Horizonte: Autêntica. 1998.

THIOLlENT, M. Metodologia da pesquisa-ação. 12.ed. São Paulo: Cortez. 2003.

TRAVAGLIA, Luiz Carlos. Letramento e conhecimento linguístico. Letras \& Letras. Universidade Federal de Uberlândia, v.31, n.3, p. 158-172. Minas Gerais, 2015.

TRIPP, D. Pesquisa-ação: uma introdução metodológica. Educação e pesquisa, v. 31, n. 3, p. 443-466, 2005

ZUCHETTI, D. T.; MOURA, E. O. G. Práticas Educativas e formação de Educadores: novos desafios no campo social. Revista Ensaio, v.18, v. 66, p. 9-28, 2010. 